\title{
SUSTENTABILIDADE NA CONSTRUÇÃO DO INSTITUTO BALEIA JUBARTE: TÉCNICAS DE BIOCONSTRUÇÃO
}

\author{
SUSTAINABILITY IN CONSTRUCTIVE 'BALEIA JUBARTE INSTITUTE': \\ BIOCONSTRUCTION TECHNIQUES
}

BRUNA DA SILVA BATISTA

Universidade do Oeste Paulista, Pós Graduação em Engenharia Urbana, Presidente Prudente, SP

E-mail: eng.brunabatista@gmail.com

RESUMO - A bioconstrução foi a alternativa escolhida para desenvolver o projeto do Instituto Baleia Jubarte, garantindo uma construção sustentável em equilíbrio com o meio ambiente. As técnicas construtivas da bioconstrução geram redução de energia, transporte, impacto ambiental e custos. $O$ trabalho objetiva apresentar as técnicas construtivas utilizadas, incorporando métodos tradicionais aliados a métodos inovadores de maneira racional. A bioconstrução é capaz de assegurar padrões de qualidade aos ecossistemas construídos, satisfazendo as demandas das atividades humanas com redução de impactos ambientais. O levantamento das medidas sustentáveis empregadas no projeto implica a adoção de novos princípios e padrões de consumo conscientes. Com uma metodologia realizada por meio do método qualitativo, apresentam-se as ações sustentáveis aplicadas, através da bioconstrução como o mecanismo guia. A construção é um marco que demonstra a possibilidade de aliar técnicas sustentáveis e obter resultados satisfatórios de eficiência energética, isolamento térmico e acústico, resistência, qualidade, durabilidade, sustentabilidade e efeito estético agradável.

Palavras-chave: Construção Sustentável, Bioconstrução, Bioarquitetura, Técnicas Construtivas, Autoconstrução.

ABSTRACT - The Bioconstruction was the chosen alternative to develop 'Baleia Jubarte Institute' project, guaranteeing a sustainable construction in balance with the environment. The constructive techniques of bioconstruction generate energy reduction, transportation, environmental impact and costs. The work aims to present the constructive techniques used, incorporating traditional methods allied to innovative methods in a rational way. The Bioconstruction is able to ensure quality standards for built ecosystems, meeting the demands of human activities with reduced environmental impacts. The survey of the sustainable measures employed in the project implies the adoption of new conscious consumption principles and consumption patterns. With a methodology carried out using the qualitative method, the sustainable actions applied through bioconstruction as a guiding the mechanism are presented. The construction is a milestone that demonstrates the possibility of allying sustainable techniques and obtains satisfactory results of energy efficiency, thermal and acoustic insulation, resistance, quality, durability, sustainability and pleasant aesthetic effect.

Keywords: Sustainable construction, Bioconstruction, Bioarchitecture, Constructive techniques, Self-construction. 


\section{INTRODUÇÃO}

Durante a Conferência das Nações Unidas a Rio 92, a Comissão Mundial para o Meio Ambiente (CMMAD) desenvolveu o relatório Nosso Futuro Comum que define o conceito de desenvolvimento sustentável com (1991, p. 46):

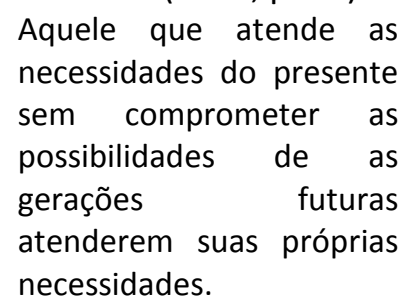

De acordo com Araújo (2008), A construção sustentável é uma técnica construtiva que atende as demandas da edificação assegurando a redução dos impactos ao meio ambiente em que está inserida, as intervenções são realizadas de maneira consciente e aliadas a qualidade de vida, com equilíbrio e em conformidade com o conceito de sustentabilidade.

O Instituto Baleia Jubarte (IBJ), localizado na Praia do Forte, no município de Mata de São João, litoral norte da Bahia, procura fortalecer práticas sustentáveis, em sua construção foram adotadas ações e princípios de conservação da natureza, em busca de sintonia com sua missão principal: "conservar as baleias jubarte contribuindo para harmonizar a atividade humana com a preservação do patrimônio natural".

Procurando utilizar técnicas construtivas em plena harmonia com o meio ambiente, a bioconstrução surgiu como a melhor opção para construção da unidade, pois incorpora o conceito de sustentabilidade em toda rotina, uma vez que os materiais e métodos empregados produzem baixo impacto na natureza.

Além da possibilidade de conscientizar e capacitar a população local para as vantagens do desenvolvimento de práticas de bioconstrução. Integrar técnicas construtivas tradicionais com as técnicas inovadoras, com estratégias voltadas a suprir as demandas dos usuários é característica fundamental da bioconstrução (DETHIER, 1982).

A bioconstrução, também conhecida como construção natural, é uma prática com experiência de centenas de anos na história mundial, a características principal desta técnica é a utilização de materiais próximos ao local da obra, evitando desperdícios com transportes, energia e industrialização. As iniciativas da bioconstrução adotadas possibilitaram obter conforto térmico, destinação adequada dos resíduos, economia de energia e água.

As técnicas construtivas sustentáveis foram sempre presentes ao longo dos anos, segundo Sattler (2007, p. 55):

Muito embora a história
do homem sempre tenha
sido acompanhada de
exemplos de construções
em harmonia com o meio
ambiente, foi a década dos
anos 1970 a que
proporcionou o início de
uma das mais pródigas
fases, propiciando o
surgimento de um
movimento que aspirava
por construções dessa
natureza. Os princípios são
mais ou menos os
tradicionais, presentes ao
longo da história, mas, a
partir da década de 90 eles
passaram a receber a
denominação de projetos
sustentáveis ou mais
sustentáveis.

No planejamento da construção, na escolha dos materiais a serem empregados foi considerado o ciclo de vida de cada material e fatores como: manutenção, durabilidade, possibilidades de reuso, reciclagem e disponibilidade próxima ao local. Deste modo para a construção foram eleitos os materiais não tóxicos e provenientes de fontes renováveis, de acordo com Instituto de Tecnologia Intuitiva e Bio-arquitetura (Tibá).

O presente trabalho tem como objetivo principal relatar as técnicas sustentáveis da bioconstrução aplicadas na construção do espaço Instituto Baleia Jubarte, de caráter exploratório através de revisão de literatura.

\section{METODOLOGIA}

Quanto à abordagem, esta pesquisa tem natureza aplicada, apresentando percepção prática por meio do método descritivo, realizada no campo das ciências sociais, a partir do estudo de caso específico e pesquisa bibliográfica, através de uma abordagem qualitativa. Sendo necessária a verificação e análise dos fenômenos 
e suas relações, para alcançar as conclusões gerais da pesquisa.

O projeto do Instituto Baleia Jubarte priorizou ações de sustentabilidade, unindo conceitos de urbanismo, arquitetura e ecologia, com a intenção de provocar mudanças de atitude em seus usuários, visitantes e colaboradores, sensibilizando e transformando mudanças na percepção do meio ambiente e nos padrões de consumo. De acordo com Bitoun (2003, p. 299) ocorre um "entrelaçamento entre a desigualdade social e a degradação do meio na formação de um ambiente urbano de baixa qualidade".

Em relação à natureza, esta pesquisa tem caráter aplicado, com o objetivo de fornecer conhecimento prático efetivo, aplicado a resolução de adversidades específicas.

Os objetivos se referem a uma pesquisa exploratória, pois busca apresentar as etapas e ações desenvolvidas ao longo do projeto para superar as dificuldades encontradas e oferecer o desempenho almejado, com levantamento bibliográfico e análise de exemplos, caracterizando a fase inicial de uma investigação ampla, com propósito de obter informações por meio de dados qualitativos.

Por classificar-se como pesquisa bibliográfica, recorre-se a documentação indireta, procurando informações detalhadas sobre o tema do presente trabalho. Portanto as referências são adquiridas em fontes secundárias, como artigos, livros e páginas eletrônicas, elaborados por autores do mesmo campo de pesquisa.

As etapas metodológicas praticadas no desenvolvimento da pesquisa, e realização dos objetivos, são estruturadas em estágios diferentes e dependentes.

A fase inicial tem objetivo de garantir a estrutura da pesquisa, proporcionando os dados e informações necessários para organizar o trabalho. O primeiro passo está voltado para uma revisão e análise criteriosa de bibliografia sobre sustentabilidade e conceitos de construção sustentável. Esta etapa busca fornecer base de conhecimento da pesquisa.

A segunda fase está voltada ao estudo da bioconstrução, com verificação dos conceitos, origem, técnicas, fatores positivos e negativos, com embasamento teórico focado nos princípios éticos, ecológicos e de design, objetivando garantir conhecimento específico sobre as alternativas construtivas adotadas no projeto.
Por fim, a terceira fase corresponde a verificação aplicada ao projeto em relação a implantação, intervenções no local, sistemas construtivos, escolha dos materiais, destinação dos resíduos, desempenho social, eficiência energética, redução de custos, qualidade e conforto da construção, caracteriza as ações de exemplos, estratégias de implementação e recomendações com potencial de ser reproduzidas em todo tipo de construção.

\section{RESULTADOS}

A elaboração do projeto Instituto Baleia Jubarte contou com a consultoria do Instituto de Tecnologia Intuitiva e Bio-arquitetura (Tibá), sob a coordenação do bioarquiteto Peter Van Legen. Inaugurado em 2006, o espaço foi criado para atender oficinas e atividades educacionais a comunidade local e visitantes, demonstrando um meio capaz de aliar evolução, conforto, qualidade e conservação ambiental, para Sattler (2007) a qualidade do ambiente promove a qualidade de vida dos usuários.

A construção civil consume $40 \%$ dos matérias e recursos por ano no mundo, como madeira extraída, energia elétrica, e água potável, os níveis de emissão de dióxido de carbono crescem cada vez mais, derivado da produção de energia, através do consumo de combustíveis não renováveis, que abastece as construções, caracterizando uma economia insustentável (SOARES (2007).

Durante a construção, para assegurar a sustentabilidade da obra, garantindo durabilidade, alguns métodos foram utilizados, tais como: análise do processo produtivo, da extração do material até a reintegração com a natureza, máximo aproveitamento dos matérias e redução na produção de resíduos, escolha de estratégias construtivas com a utilização de matérias existentes nas proximidades. Para Soares (2007), a bioconstrução é uma técnica capaz de garantir o acesso de recursos de forma equilibrada e sem excedentes.

Os métodos inovadores empregados garantiram a funcionalidade da construção, utilizando técnicas como: paredes de adobe, teto verde, madeira de reflorestamento, filtro biológico que possibilita a purificação das águas cinzas (águas originárias da pia e do chuveiro), podendo ser reutilizada no solo. Além do processo de controle dos resíduos orgânicos 
através da compostagem, produzindo adubo, e o banheiro seco, que não utiliza água.

As técnicas de bioconstrução empregadas no projeto garantem a sustentabilidade e o equilíbrio entre obra e natureza, utilizando materiais disponíveis no meio ambiente, reaproveitados e reciclados, tais como: pedras, bambu, eucalipto, terra, coco, garrafas de vidro usadas, piaçava, entre outros materiais. $O$ espaço possui área total de $3.500 \mathrm{~m}^{2}$, conta com anfiteatro coberto, com capacidade para até 70 pessoas. Os banheiros do espaço possuem piso de azulejo hidráulico reciclado, luminárias de caixas de ovos e tábuas de maçaranduba proveniente de demolição. Além do teto verde e das alvenarias em adobe, tornando o Espaço Baleia Jubarte uma atração impressionante.

Para a construção foi contratada mão-deobra local e mutirões foram organizados, todos os envolvidos participaram de processo de capacitação, o autor da obra Peter Van Legen, foi responsável pela orientação das eco-técnicas e explicação do desempenho total do projeto. Para Capra (2001, p. 09)

Há soluções para os
principais problemas de
nosso tempo, algumas
delas até mesmo simples.
Mas requerem uma
mudança radical em
nossas percepções, no
nosso pensamento e nos
nossos valores.

A construção do Instituto Baleia Jubarte, demonstra definitivamente que projetos de bioconstrução são técnicas eficientes e inovadoras, capazes de atender às expectativas de qualidade da construção, redução da poluição ambiental, utilização de materiais acessíveis, controle de temperatura independente das condições climáticas, diminuição de energia, possibilidade de reuso dos materiais, baixo custo e os métodos construtivos podem ser executados por qualquer pessoa, mesmo sem experiência, uma vez que para a execução da construção apenas é necessária utilização de ferramentas simples, incentivando a autoconstrução.

\section{DISCUSSÃO}

Ao realizar esta pesquisa verificou-se que após a elaboração do projeto, o passo seguinte foi a escolha do material a ser utilizado na construção, priorizando o uso dos materiais existentes em grande quantidade na região, desde que sua extração não cause impactos ambientais negativos. Para a seleção dos materiais levou-se em conta o estudo do ciclo de vida dos materiais, a fim de garantir a durabilidade e sustentabilidade da construção.

\section{Prompt (2008, p. 10) assegura que:}

Devemos pensar na
sustentabilidade em nível
local (cuidado com a terra,
manejo sustentável das
matas, extração
consciente dos recursos) e
em nível global. Para
colaborar para a
construção de um mundo
mais sustentável devemos,
por exemplo, consumir
com cuidado, dando
preferência a produtos da
região, e optar pelo uso de
energias renováveis.

A obra teve início com a fundação, como demonstrado na Figura 1, executada com rochas naturais e eucalipto da região sem tratamento, também utilizado na estrutura da construção, para não introduzir toxinas ao espaço. A rocha é um material de qualidade excelente, garante resistência as cargas atuantes e impermeabilidade. A obra concluída agrega todos os conceitos da bio-arquitetura. Inclusive o jardim, que inclui uma área de compostagem, horta, viveiro e sistemas agroflorestais.

Figura 1. Execução da estrutura com rochas e eucalipto.

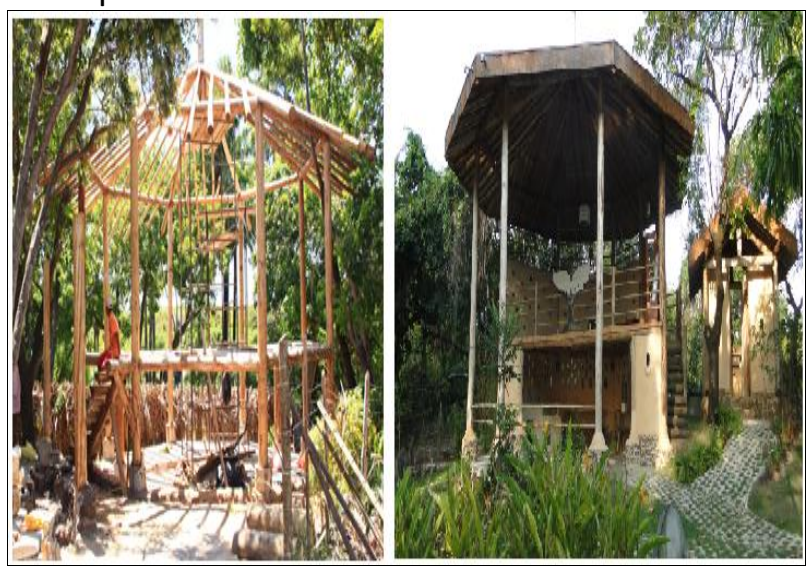

Fonte: Tibá - Instituto de Tecnologia Intuitiva e Bioarquitetura (2017).

Para as alvenarias a técnica sustentável adotada foi o adobe, são blocos feitos a partir da 
mistura de terra, água e fibra vegetal resistente, geralmente moldados em formas de madeira, em um processo artesanal, como pode ser identificado na Figura 2. A confecção dos adobes não produz emissão de gases tóxicos, por utilizar secagem natural. Os blocos de adobe são assentados com a mesma mistura de sua composição, produzem alvenarias de fechamento e alvenarias estruturais, além de garantir qualidade de isolamento térmico e acústico, resistência ao fogo, impermeabilidade e facilidade de concerto.

Figura 2. Confecção dos adobes (esquerda) e assentamento dos blocos de adobe (direita).

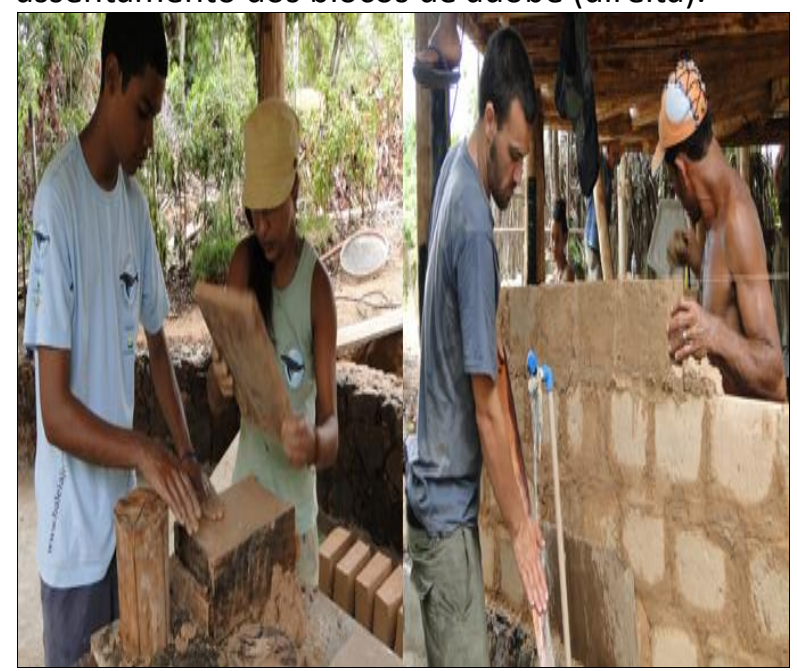

Fonte: Tibá - Instituto de Tecnologia Intuitiva e Bioarquitetura (2017).

Outra técnica utilizada para execução das paredes foi o pau-a-pique, como pode ver visto na Figura 3, também conhecido como taipa de mão. O pau-a-pique é um método simples, demanda a construção de uma trama de fibra natural (fibra de coco e piaçava), preenchida manualmente com terra argilosa. Necessita do uso de formas até a completa secagem da estrutura. É possível produzir blocos e painéis. $\mathrm{O}$ pau-a-pique garante qualidade térmica e bom acabamento.
Figura 3. Pau-a-pique com fibra de coco e piaçava.

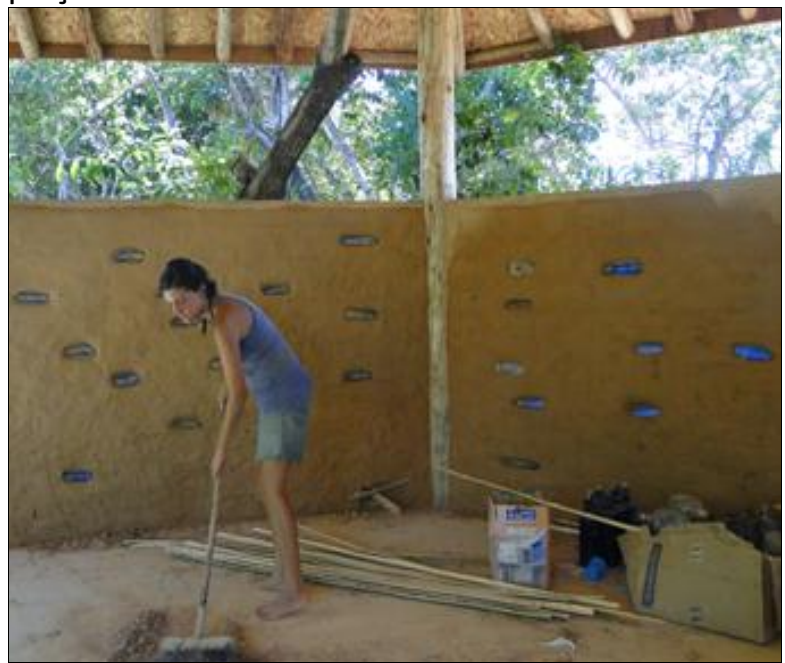

Fonte: Tibá - Instituto de Tecnologia Intuitiva e Bioarquitetura (2017).

Foram construídas esquadrias do tipo veneziana e treliça utilizando bambu mirim, colhido na fazenda vizinha, partido ao meio, pregado com a parte reluzente voltada para o exterior, evitando reflexos na parte interna. Este modelo permite a entrada da luz no ambiente interno e bloqueia a visão de fora para dentro, como pode ser observado na Figura 4.

Figura 4. Esquadrias de bambu.

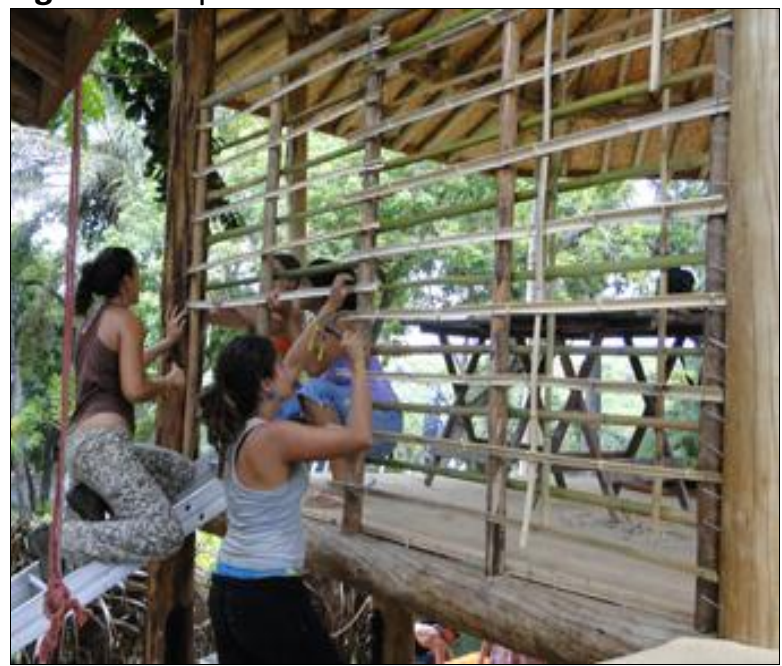

Fonte: Tibá - Instituto de Tecnologia Intuitiva e Bioarquitetura (2017).

Considerando que o principal componente na produção das paredes foi a terra, o revestimento a ser utilizado deve certificar a regularidade da umidade do ar através das alvenarias de terra, evitando o surgimento de fissuras, portanto optou-se por reboco natural, de acordo com a Figura 5, adotando a cal como estabilizante em substituição ao cimento e 
materiais de origem natural como terra, esterco equino, areia e cal.

Figura 5. Revestimentos.

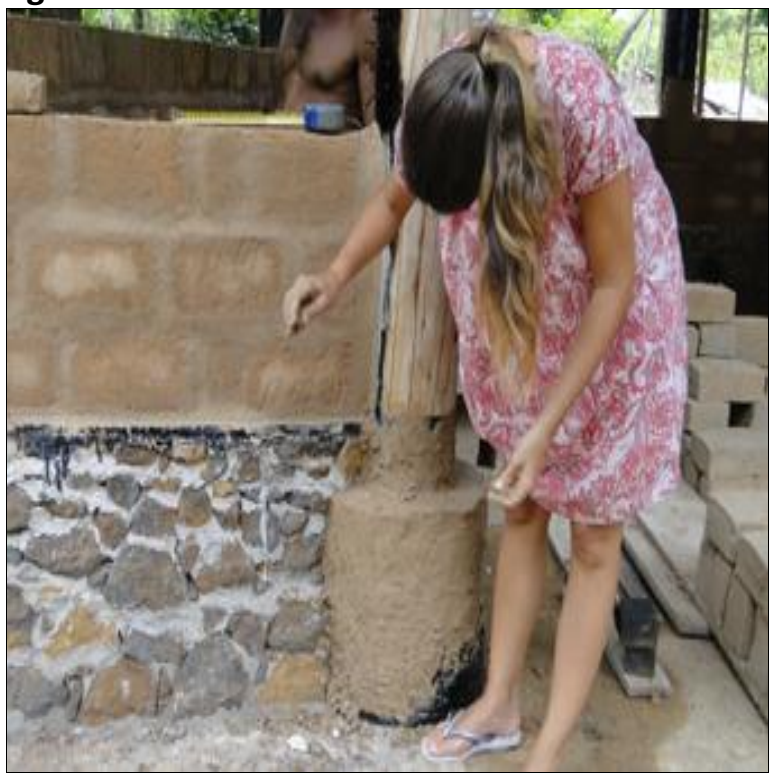

Fonte: Tibá - Instituto de Tecnologia Intuitiva e Bioarquitetura (2017).

Para a construção das pias e sanitários secos, a técnica construtiva eleita foi 0 plastocimento, constituído por uma argamassa de cimento e areia e sacos plásticos, com identificado na Figura 6. Sobre um terreno plano forrado com jornal, é disposto o molde do elemento que se pretende obter, este é preenchido com a argamassa, nivelado e coberto com saco plástico, constituindo a primeira camada, repete-se o procedimento anterior, configurando a segunda camada, retira-se os moldes, que podem ser reutilizados. A placa deve secar por uma semana, protegida do sol. A base de apoio do elemento pode ser feita com tijolos ou pedras.
Figura 6. Fabricação das placas de plastocimento.

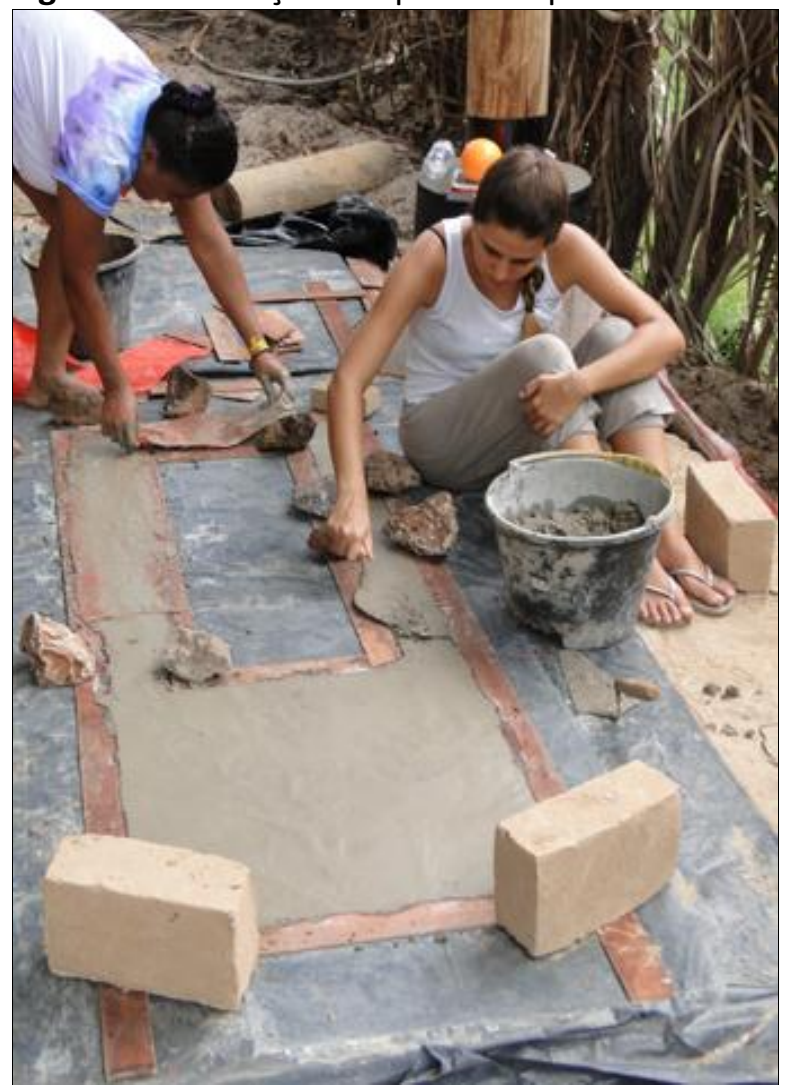

Fonte: Tibá - Instituto de Tecnologia Intuitiva e Bioarquitetura (2017).

Os sanitários foram construídos visando atender os princípios de preservação do meio ambiente e economia de água, portanto o sanitário seco foi eleito como solução. $O$ banson é um sanitário seco, que utiliza o princípio da compostagem aeróbica em câmaras, para transformar a mistura de dejetos e resíduos orgânicos domésticos em adubo. Na construção do bason, as placas de plastocimento foram confeccionadas separadamente, unidas por arame e aplicado argamassa nas juntas. Após o período de secagem de um semana, a peça de 200 quilos pode ser instalada, como visto na Figura 7. Para ventilar o bason, foi colocado um tubo de PVC de $100 \mathrm{~mm}$, pintado de preto fosco na parte exposta ao sol. $\mathrm{O}$ calor do sol possibilita uma corrente de exaustão do ar para o exterior. Todas as entradas e saídas foram protegidas com tela. Para facilitar a decomposição da matéria orgânica, foi colocado no fundo da câmara folhas secas, cinzas e serragem. 
Figura 7. Instalação do bason (esquerda). O Bason XL 2010 (direita).

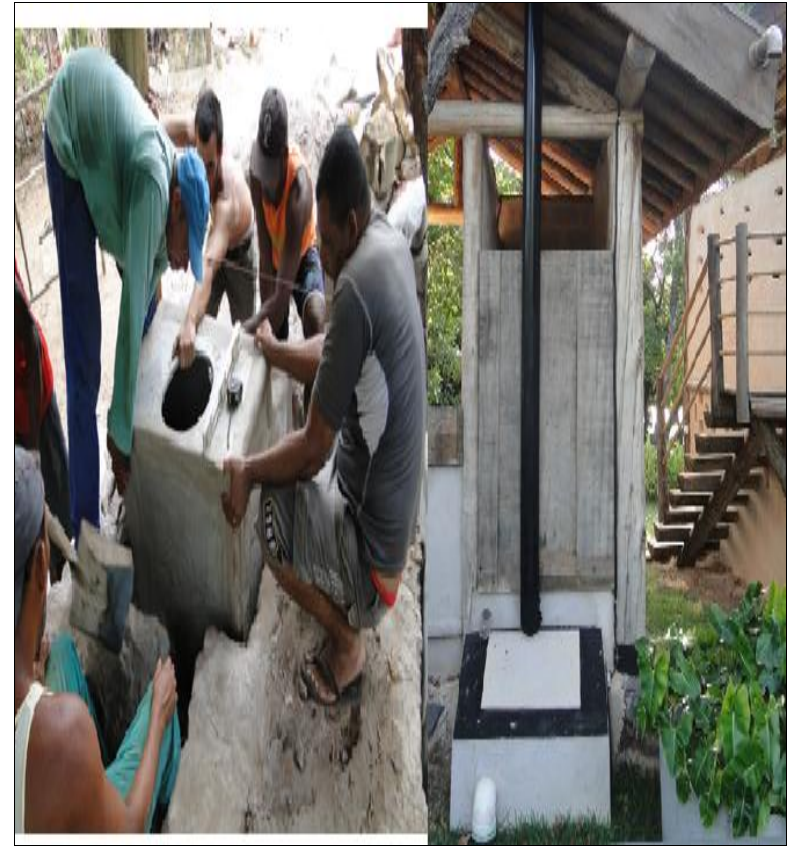

Fonte: Tibá - Instituto de Tecnologia Intuitiva e Bioarquitetura (2017).

Nos banheiros foi utilizado piso de azulejo hidráulico reciclado de um casarão do Pelourinho. Luminárias de caixas de ovos, tábuas de maçaranduba de demolição. Houve muito reuso e reciclagem de materiais, como observado na Figura 8.

Figura 8. Banheiros.

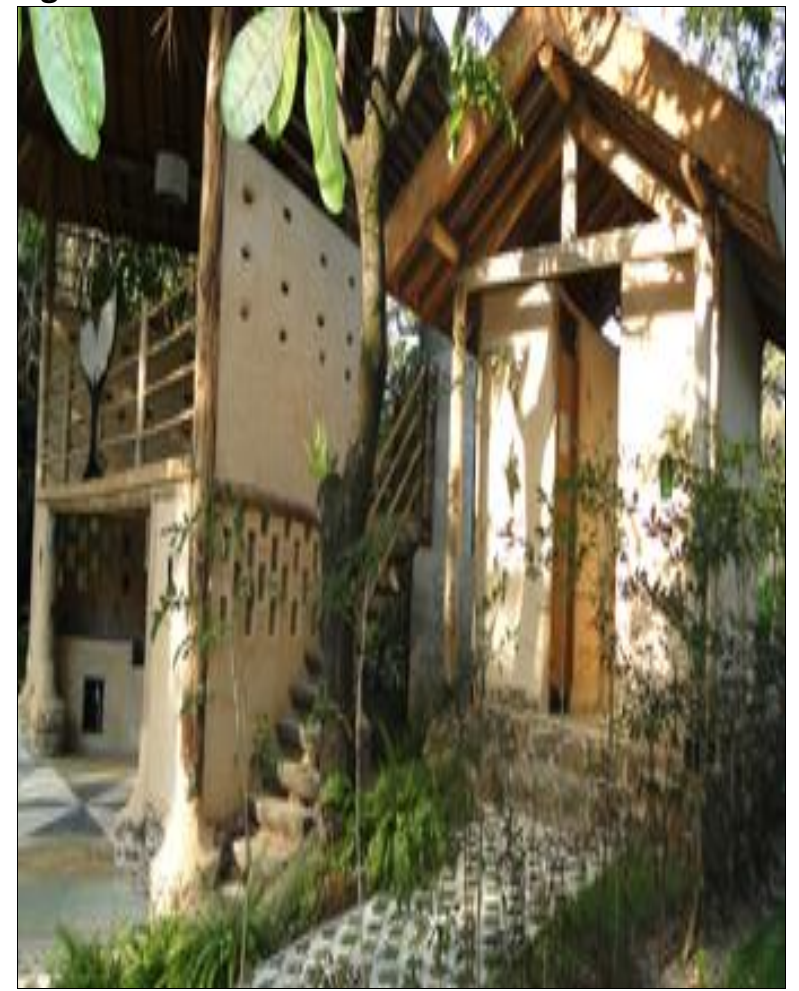

Fonte: Tibá - Instituto de Tecnologia Intuitiva e Bioarquitetura (2017).
As águas provenientes das pias, chuveiro e lavatórios, denominas como águas cinzas, são destinadas aos filtros biológicos, como identificado na Figura 9. Os filtros são tanques construídos em alvenaria de tijolos ou blocos sobre uma placa de concreto, os materiais constituintes, brita e areia, são depositados no fundo do filtro. A passagem lenta da água pela areia, permite que se forme uma camada de limo que será responsável por realizar a filtragem fina. O limo é um excelente filtro biológico que retém e digere microrganismos nocivos presentes na água. Após o processo de filtragem a água é reutilizada, podendo ser aplicada em irrigações superficiais, lavagem de pátios, etc.

Figura 9. Filtro biológico para as águas cinza.

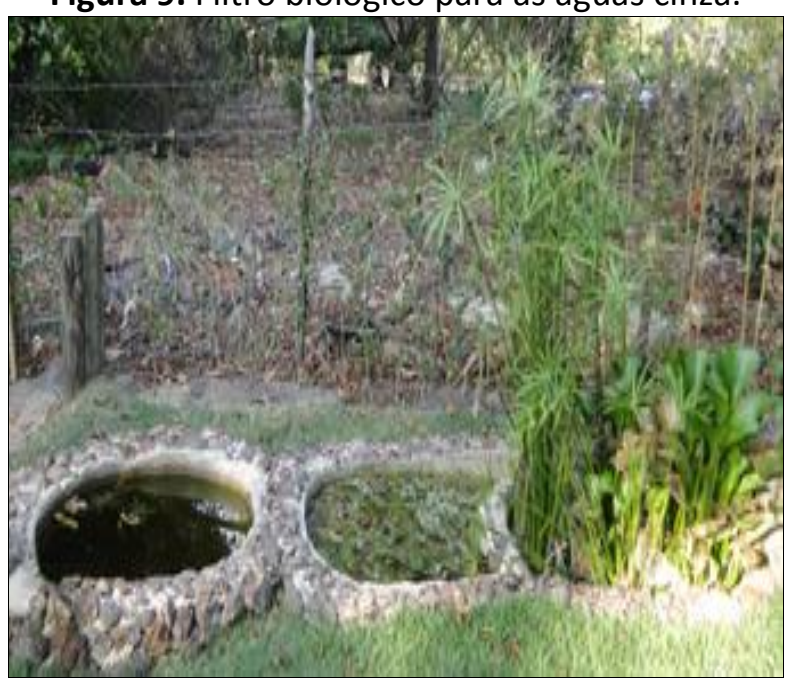

Fonte: Tibá - Instituto de Tecnologia Intuitiva e Bioarquitetura (2017).

Para a estrutura da cobertura foram utilizados materiais como madeira e bambu de diferentes dimensões, constituindo uma base ondulada, evitando o deslizamento da grama. Sobre as tábuas foi fixada uma membrana impermeabilizante (plástico), ao longo do telhado foi colocado um tubo furado, que atua com dreno, este é coberto por uma camada de brita para evitar a obstrução do dreno, além de atuar como pré-filtro para água da chuva. $O$ telhado é coberto por placas de grama, como mostrado na Figura 10. O telhado verde oferece isolamento térmico e acústico, resistência ao fogo, vida útil longa, pouca necessidade de manutenção além de agradável efeito estético. 
Figura 10. Teto verde.

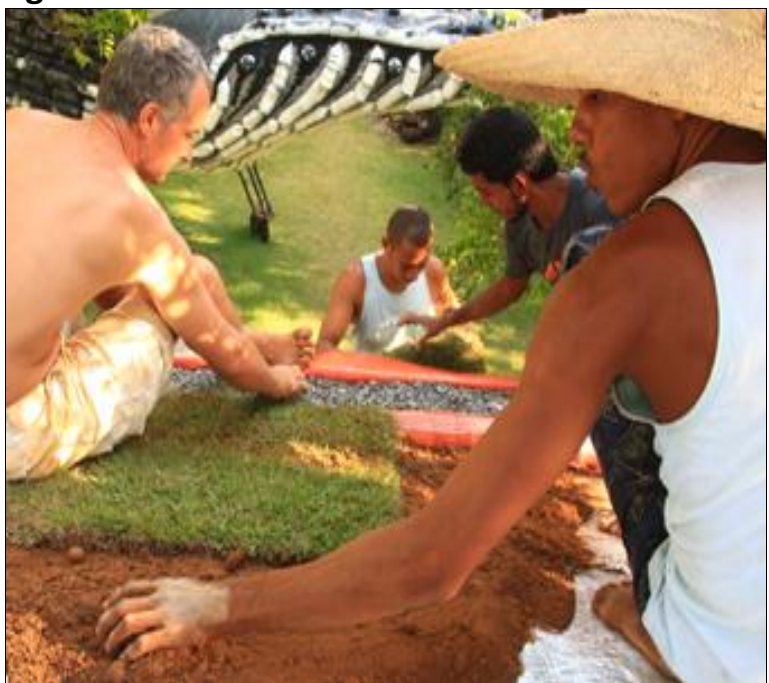

Fonte: Tibá - Instituto de Tecnologia Intuitiva e Bioarquitetura (2017).

Para armazenar a água da chuva captada, foi instalada uma cisterna, como pode ser observado na Figura 11, construída com manilhas de concreto armado, com capacidade de 1.800 litros. A saída da água inclui um filtro natural de areia e brita.

Figura 11. Cisterna em manilhas de concreto armado.

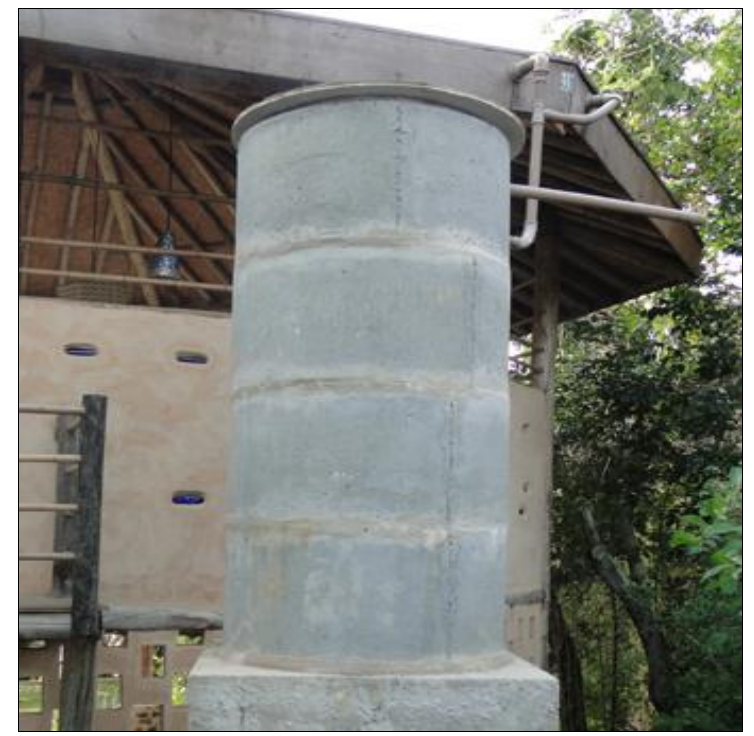

Fonte: Tibá - Instituto de Tecnologia Intuitiva e Bioarquitetura (2017).

\section{CONCLUSÃO}

A construção do Instituto Baleia Jubarte utilizando técnicas da bioconstrução gerou efeitos positivos na estrutura edificada e em todos os envolvidos no projeto, funcionários do Instituto e população local, que participaram do processo de capacitação e desenvolvimento das diferentes técnicas construtivas.

As técnicas da bioconstrução garantiram a obra viabilidade de aproveitar os vários elementos presentes na região e processo de reutilização de materiais, além de difundir o conhecimento prático de técnicas de autoconstrução, possibilitando a população local novas oportunidades.

Este método construtivo demonstrou que construções sustentáveis oferecem inúmeras vantagens em relação aos sistemas construtivos convencionais, pois proporciona conforto, eficiência, durabilidade, estética e custo acessível, além de utilizar materiais não tóxicos.

O projeto do Instituto Baleia Jubarte prova que as edificações podem exercer exemplos práticos de sustentabilidade ambiental e práticas éticas de construção, configurando um bom modelo a ser seguido.

\section{REFERÊNCIAS}

ARAÚJO, M. A. A moderna construção sustentável. Disponível em: <http://www.idhea.com.br/artigos_entrevistas.a sp>. Acesso: 21 janeiro 2017.

BITOUN, J.; CARLOS, A. F.; LEMOS, A. Os Embates entre as Questões Ambientais e Sociais no Urbano. Dilemas Urbanos: Novas Abordagens. São Paulo: Contexto, 2003. p. 299-307.

BUARQUE, S. C. Construindo o Desenvolvimento Sustentável. Recife: Garamond, 2001.

CAPRA, F. A Teia da Vida. São Paulo: Cultrix, 2001. p. 256.

CMMAD - Comissão Mundial sobre Meio Ambiente e Desenvolvimento. Nosso Futuro Comum. Rio de Janeiro: Fundação Getúlio Vargas, 1991. p. 46.

DETHIER, J. Arquiteturas de Terra, ou o futuro de uma tradição milenar. Lisboa: Fundação Culouste Gulbenkian, 1993.

JACOBI, C. M. Ecologia Urbana: Bases Ecológicas para o Desenvolvimento Sustentável. 2002. Disponível em: http://aprender.unb.br/mod/resource/view.php? $\mathrm{id}=2875$ > . Acesso: 21 janeiro 2017. 
JOHN, V. M.; OLIVEIRA, D. P.; LIMA, J. A. R. Levantamento do Estado da Arte: Seleção de Materiais. Projeto Tecnologias para Construção Habitacionais mais Sustentável. São Paulo: FINEP, 2007.

LAMBERTS, R.; DUTRA, L.; PEREIRA, F. Eficiência Energética na Arquitetura. São Paulo: PW, 1997.

LENGEN, J. V. Manual do Arquiteto descalço. São Paulo: B4 Editores. 1a edição. 2014.

PROMPT, C. Curso de Bioconstrução. Ministério do Meio Ambiente; Brasília, 2008. Disponível em: <http://www.mma.org.gov.br>. Acesso: 21 janeiro 2017.

SATTLER, M. A. Habitações de baixo custo mais sustentáveis: a casa alvorada e o centro experimental de tecnologias habitacionais sustentáveis. Porto Alegre: Coleção Habitare, Finep. 2007.

SOARES, A. Soluções sustentáveis: construção natural. Mais Calango Editora. 2007. p. 64.

TIBÁ - Instituto de Tecnologia Intuitiva e Bioarquitetura. Disponível em $<$ http://www.tibarose.com/port/projetosbaleia_jubarte.php>. Acesso: 21 janeiro 2017. 